\title{
Phenyltetrazole compounds inhibition influence on mild steel corrosion in acidic solution
}

\author{
A.A. Mahmmod,* ${ }^{(i)}$ M.K. Mohammed ${ }^{(D)}$ and M.A. Sultan \\ Chemical Engineering Department, Engineering College, University of Diyala, Iraq \\ *E-mail: alnuimiadiba@yahoo.com
}

\begin{abstract}
Inhibitors in general work to reduce the corrosion process in industrial sectors. Predominantly organic corrosion inhibitors, including phenyltrazole compounds, 5-(4-chlorophenyl)- $1 \mathrm{H}$ tetrazole ((CL-PT) and 5-(4-methoxyphenyl)- $1 H$-tetrazole (MO-PT) \& 5-phenyl-1H-tetrazole (PT) were employed in this work to protect mild steel or metal samples against corrosion in acidic medium $(2.5 \% \mathrm{HCl})$. Experimentally, the research mainly studied the effect of an inhibitor type, phenyltetrazole compounds, as an corrosion inhibitor on mild steel exposure, using a weight loss technique as a means for measuring corrosion rate. We explored the weight loss measurements to monitor the corrosion rate and it was found that phenyltetrazole compounds worked efficiently in decreasing mild steel corrosion in hydrochloric acid medium. The corrosion-rate measurements were reported under an acidic medium at the concentration range of $(0.001-0.004 \mathrm{M})$. The relationship between the inhibitors' concentration and corrosion rate was measured at two different data sets for each inhibitor at 6 hours immersion time in corrosive media. The immersion time of all experiments was constant and the results gained from the present work showed that the corrosion rate decreased with an increase in an inhibitor concentration. The maximum effectiveness for the inhibitors reached up to a value of $95.0 \%$ at $0.004 \mathrm{M}$ at $25^{\circ} \mathrm{C} \& 6 \mathrm{hr}$ immersion time of mild steel sample in the corrosive acid.
\end{abstract}

Keywords: corrosion, phenyltetrazole compounds, mild steel, weight loss technique, hydrochloric acid.

Received: August 5, 2020. Published: October 26, 2020

doi: $\underline{10.17675 / 2305-6894-2020-9-4-9}$

\section{Introduction}

Metals and mild steel are vastly consumed in most chemical industries due to their availability, low cost, but easily corroded if they are not properly protected . Many studies have been devoted to addressing corrosion problems in a multidisciplinary field in chemistry and engineering [1-8]. Iron or mild steel are vulnerable to corrosion processes when subjected to extensively acidic environments at industrial processes such as acid scrub, descaling and other operations in oil and gas extraction [9-11]. These acidic media may give rise to corrosion causes after scaling removal operations [12-15]. Various researches have been done to prohibit the corrosion mechanisms on surfaces of metals. Methods of corrosion reduction include the application of protective coatings, alloying, anodic, and cathodic protection and the use of a different class of inorganic and organic inhibitors [16-25]. 
Natural products and synthesized organic compounds have been used and been reported to be effective corrosion inhibitors. These materials contain nitrogen molecules in their chemical compositions, which are adsorbed on mild steel surfaces [26-28]. The most common inhibiters are organic compounds encompassing functional groups and $\pi$-electrons disclosed in double or triple bonds. In addition, those organic compounds materials are considered efficient inhibitors because they displace water and thus protect surfaces from deteriorating [29-31]. To date, many heterocyclic compounds such as amine derivatives, amino acids, and imidazoline derivatives have been reported as good corrosion inhibitors of steel in acidic media. In general, heterocyclic complexes exhibit their inhibitive effects by the adsorption process through $N$ heteroatom. This adsorption mechanism is reviewed as anode corrosion inhibitors. In that perspective, anode corrosion inhibitors interact with metal to produce an insoluble layer, covering the active sites on metal surfaces, and in turn decreasing the corrosion rate [32].

\section{Experimental work}

The formation of inhibitors was carried out based on a procedure reported by P. Zachart et al. (2001) [33]. The procedure started with the synthesis of 5-phenyltetrazole, then the other phenyltetrazole compounds were made after using benzonitrile with desired substituents on the benzene ring. The chemical structures of the organic inhibitors are shown below:

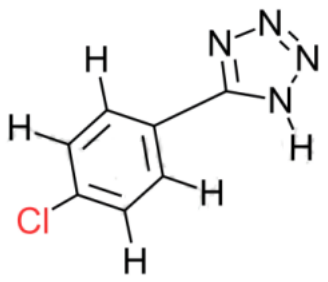

CL-PT

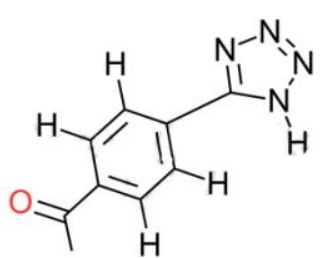

MO-PT

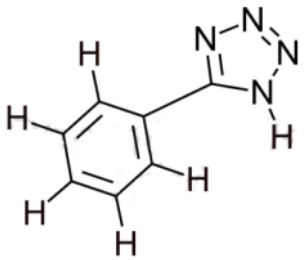

PT

The next step is the sample preparation. The sample ofmild steel used in this study is a $2 \mathrm{~cm}^{2}$ exposition surface area and its elemental compositions (\% wt.) is $\mathrm{Fe}: 99.25 \%$, C: $0.14 \%$, Cr: $0.160 \%, \mathrm{Mn}: 0.44 \%, \mathrm{Cu}: 0.146 \%$. The sample's surface was cleaned with emery paper, and was washed with distilled water and rinsed with ethanol. The sample was further placed under flow of hot air for drying. After cleaning, the sample was immersed in a $150 \mathrm{~cm}^{3}$ glass conical flask contained an acidic solution. The sample was kept in an acidic solution for 6 hours. Subsequently, it was weighed out for corrosion measurements. Last, the same process was repeated in the presence of inhibitors, and again the sample was weighed to find out the weight difference in both cases. Weight loss data were specified in absence and presence of the inhibitors, the corrosion rate unit is calculated in $\left(\mathrm{mg} / \mathrm{cm}^{2} \cdot \mathrm{h}\right)$ in the current work. Runs of experimental data completed in the presence of phenyltetrazole inhibitors investigate four different concentrations $(0.001,0.002,0.003,0.004 \mathrm{M})$, in $2.5 \% \mathrm{HCl}$ as an acidic medium. 


\section{Results and Discussion}

\subsection{Measurements of weight loss}

Corrosion rates of mild steel are explored with and without the organic inhibitors in acid solution, where the measurements are conducted at $25^{\circ} \mathrm{C}$. The addition of phenyltetrazole compounds is up to different concentration ranges $(0.001-0.004 \mathrm{M})$, and weight loss technique is mainly used to monitor the corrosion rate. The values of rates of corrosion rate are determined using the ensuing Equation 1:

$$
\mathrm{CR}=W_{1}-W_{2} / A \times t
$$

Where CR is corrosion rate $\left(\mathrm{mg} / \mathrm{cm}^{2} \cdot \mathrm{h}\right), W_{1}$ and $W_{2}(\mathrm{mg})$ are the mass before and after dipping, $A$ indicates the overall external area of sample $\left(\mathrm{cm}^{2}\right)$, and $t$ it means the time of the experiment (hours).

The \% efficiency is calculated by Equation 2:

$$
\% I E=\left(\mathrm{CR}^{0}-\mathrm{CR} / \mathrm{CR}^{0}\right) \times 100
$$

Table 1 compares the effect of the inhibitor's concentration, inhibition efficiency and corrosion rate on a mild steal in an acidic solution for all studies, while Figure 1 illustrates the relationships between the concentrations of inhibitors versus corrosion rate. Table 1 shows that mild steel is corroded significantly in the corrosive medium at the absence of organic inhibitors, recording a value of $1.10 \mathrm{mg} / \mathrm{cm}^{2} \cdot \mathrm{h}$. However, this scenario alters when the inhibitor contents are added to the surface of mild steel. It can be shown from Table 1 the corrosion rate is reduced notably at the presence of inhibitors, indicating that those materials have an efficient ability at protecting mild steel from deteriorating in an acidic medium. It was also observed that the efficiency of these organic inhibitors increases with an increase in inhibitors' concentrations Table 1 and Figure 1. At the CL-PT experiment, the reduction of corrosion starts to fall down gradually as CL-PT concentration increases, giving 95\% of CL-PT's inhibition at concentration of $0.004 \mathrm{M}$. At this point, the corrosion rate is at the lowest value, reaching to $0.055 \mathrm{mg} / \mathrm{cm}^{2} \cdot \mathrm{h}$. Moreover, the same mechanism of an inhibitor's effect is at work during the addition of MO-PT compound. The weight loss calculation shows a decrease in corrosion rate in which the organic material's concentration is $0.001 \mathrm{M}$, and its inhibitive efficiency corresponds to $89.63 \%$. The trend of the MO-PT's inhibitive effect begins to incline steadily as the concentration increases. The highest performance of the inhibitor is attained at $92.81 \%$ when the added concentration is $0.004 \mathrm{M}$. In the case of PT, the recorded data are slightly different in terms of corrosion rate numbers and efficiency percentage. The relationship between the organic inhibitor's concentration and efficiency percent remains directly related. However, the maximum efficiency percent is never measured greater than the 80 ranges. Table 1 indicates the application of the inhibitor (at $0.001 \mathrm{M}$ ) on the mild steel surface gives $83.0 \%$ of PT inhibition. Beyond that, the inhibition efficiency of the organic compound undorgoes close change. Its maximum 
performance is found to be $87.25 \%$, at $0.004 \mathrm{M}$ and the corrosion rate corresponding to this percent is found to be $0.1402 \mathrm{mg} / \mathrm{cm}^{2} \cdot \mathrm{h}$.

In addition, the data acquired in the study are further analyzed graphically. Figures 2, 3 show a plot of two variables, the concentration of inhibitors, ranging from $(0.001 \mathrm{M}-$ $0.004 \mathrm{M}$ ), versus efficiency percentage. It is noticeable that Figures 2,3 show a linear relationship, and \%Efficiency of the inhibitors is dependent of concentration at which \%Efficiency for CL-PT is reported to be the highest compared to the other two organic inhibitors at $0.004 \mathrm{M}$, thus proving CL-PT is an effective inhibitor at room temperature. This phenomenon may contribute to the strong layer formation of the CL-PT on the steel surface.

Table 1. Inhibitor concentration influence on the corrosion rate of mild steel sample in $2.5 \% \mathrm{HCl}$.

\begin{tabular}{ccccc}
\hline $\begin{array}{c}\text { Inhibitor } \\
\text { type }\end{array}$ & $\begin{array}{c}\text { Temperature } \\
\left({ }^{\circ} \mathbf{C}\right)\end{array}$ & $\begin{array}{c}\text { Concentration of } \\
\text { inhibitor }(\text { Molarity })\end{array}$ & $\begin{array}{c}\text { Corrosion rate } \\
\left(\mathbf{m g} / \mathbf{c m}^{\mathbf{2}} \cdot \mathbf{h}\right)\end{array}$ & $\begin{array}{c}\text { Efficiency } \\
(\mathbf{\%})\end{array}$ \\
\hline Nil & 25 & - & 1.01 & - \\
\hline \multirow{2}{*}{ CL-PT } & 25 & 0.001 & 0.085 & 92.27 \\
& & 0.002 & 0.077 & 93.0 \\
& & 0.003 & 0.0681 & 93.81 \\
& & 0.004 & 0.055 & 95.0 \\
\hline \multirow{2}{*}{ MO-PT } & 25 & 0.001 & 0.1141 & 89.63 \\
& & 0.002 & 0.101 & 90.82 \\
& & 0.003 & 0.089 & 91.90 \\
& & 0.004 & 0.079 & 92.81 \\
\hline \multirow{2}{*}{ PT } & 25 & 0.001 & 0.187 & 83.0 \\
& & 0.002 & 0.1718 & 84.38 \\
& & 0.003 & 0.155 & 85.91 \\
& & 0.004 & 0.1402 & 87.25 \\
\hline
\end{tabular}

\section{Conclusions}

It is noticeable that phenyltetrazole materials are influential corrosion inhibitors versus mild steel and metal surfaces. Weight loss technique is predominately employed to affirm corrosion restrain in a hydrochloric acid medium. The use of phenyltetrazole inhibitors to prevent mild steel from corrosion in a solution of hydrochloric acid is an effective choice with a weight loss process, as laboratory results show high-efficiency values for these inhibitors. Through laboratory experiments, it was found that inhibition efficiency is increased with an increase in phenyltetrazole concentrations used in this work. The CL-PT inhibitor gave the highest efficiency value (95.0\%) at the concentration $0.004 \mathrm{M}$, and the PT 
inhibitor has the lowest value $(87.25 \%)$ in the same concentration, thus the inhibitor CL-PT is considered to have an effective ability in protecting the sample from corrosion.

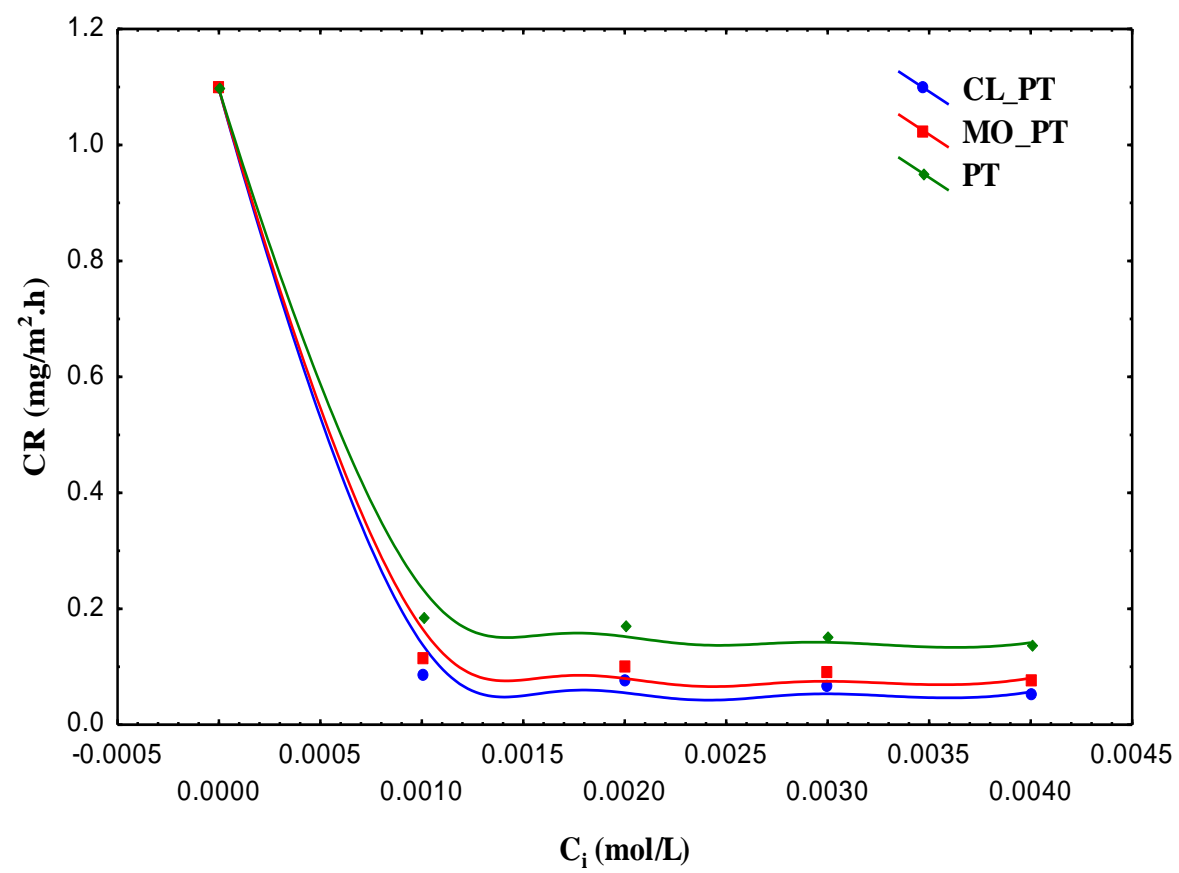

Figure 1. Effect of the concentration of phenyltetrazole substituted compounds on the corrosion rate of mild steel in hydrochloric acid.

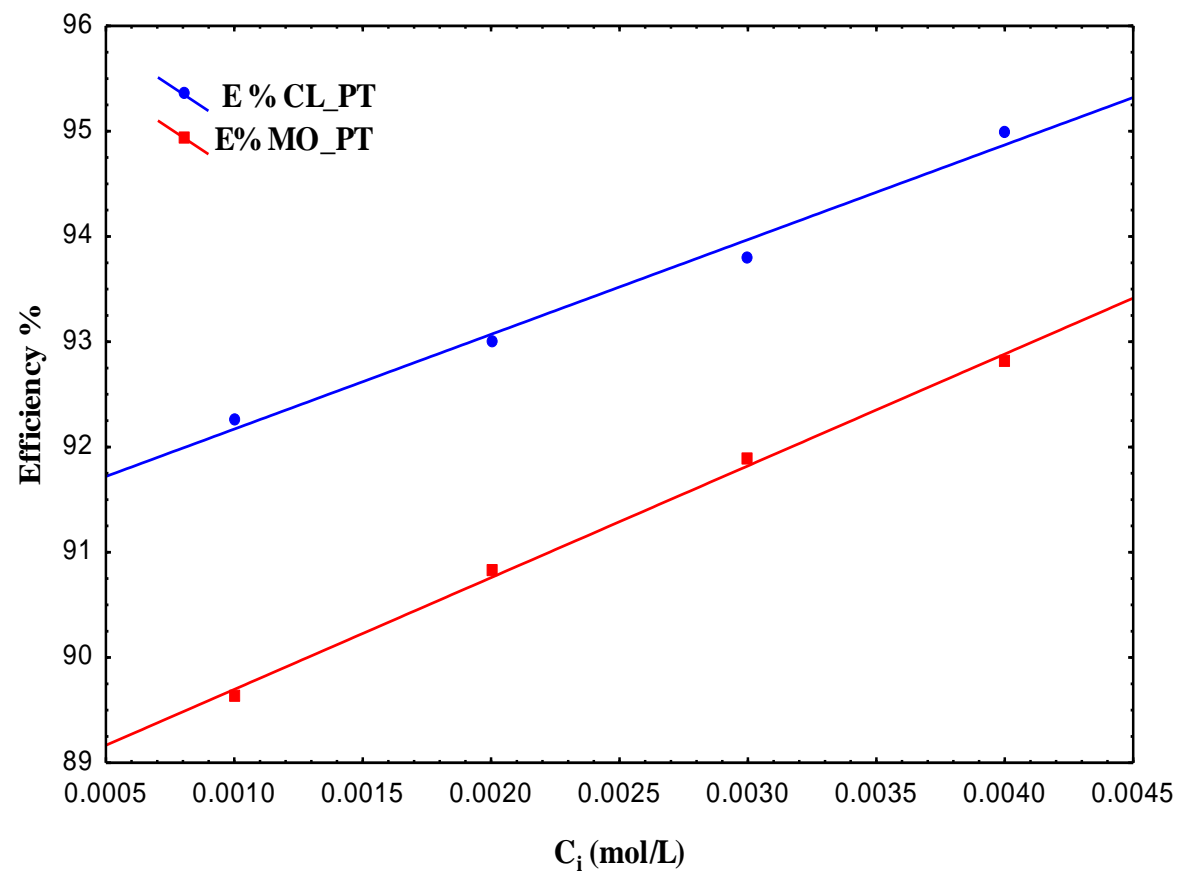

Figure 2. Efficiency of inhibitors ((CL-PT)\&(MO-PT)) vs. inhibitors concentration of mild steel in hydrochloric acid. 


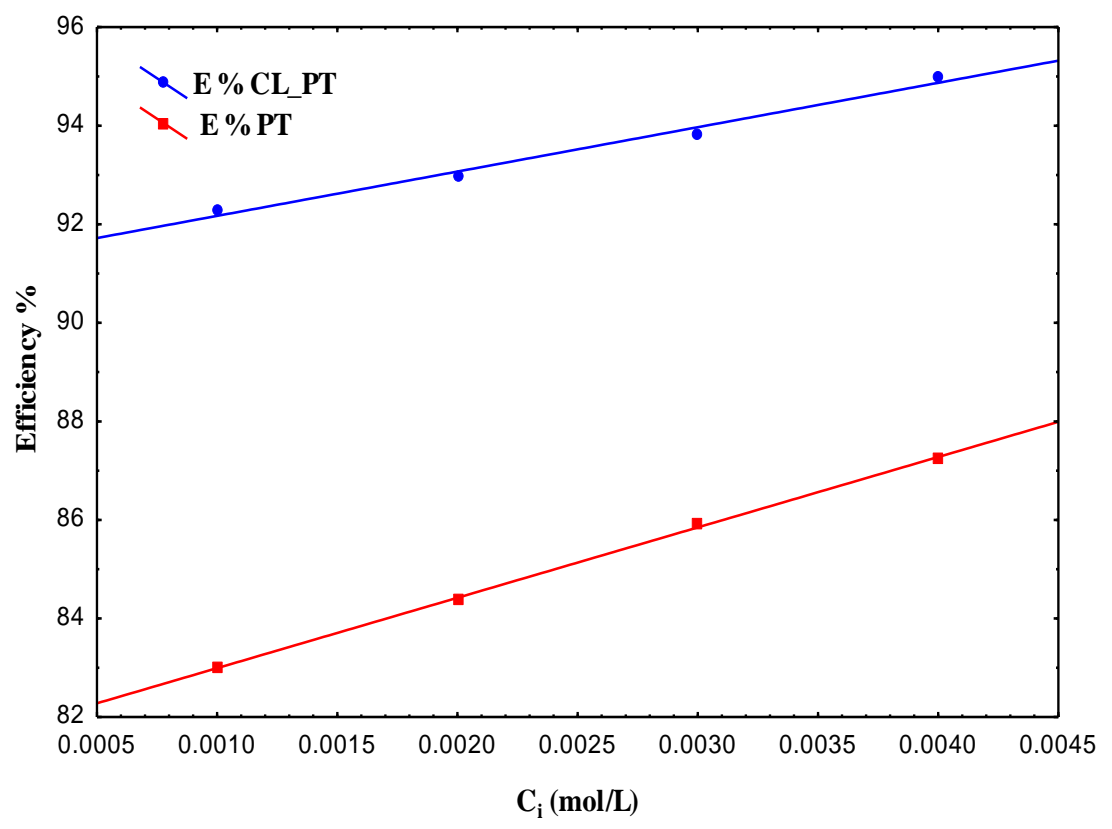

Figure 3. Efficiency of inhibitors ((CL-PT)\&PT) vs. inhibitors concentration of mild steel in hydrochloric acid.

\section{Acknowledgments}

The authors provide their appreciation to University of Diyala, Iraq for persistent support.

\section{References}

1. Adiba A. Mahmmod, Int. J. Corros. Scale Inhib., 2019, 8, no. 4, 1112-1122. doi: 10.17675/2305-6894-2019-8-4-18

2. L. Afia, R. Salghi, L. Bammou, E. Bazzi, B. Hammouti, L. Bazzi and A. Bouyanzer, J. Saudi Chem. Soc., 2014, 18, 19-25. doi: 10.1016/j.jscs.2011.05.008

3. H.I. Al-Itawi, G.M. Al-Mazaideh, A.E. Al-Rawajfeh, A.M. Al-Ma'abreh and A. Marashdeh, Int. J. Corros. Scale Inhib., 2019, 8, no. 2, 199-211. doi: 10.17675/23056894-2019-8-2-3

4. Dina A. Najeeb, Int. J. Corros. Scale Inhib., 2019, 8, no. 3, 717-725. doi: 10.17675/2305-6894-2019-8-3-18

5. A.M. Semiletov, Int. J. Corros. Scale Inhib., 2017, 6, no. 4, 449-462. doi: 10.17675/2305-6894-2017-6-4-5

6. H. Bentrah, Y. Rahali and A. Chala, Corros. Sci., 2014, 82, 426-431. doi: 10.1016/j.corsci.2013.12.018

7. Y. Elkacimi, M. Achnin, Y. Aouine, M.Ebn Touhami, A. Alami, R. Touir, M. Sfaira, D. Chebabe, A. Elachqar and B. Hammouti, Port. Electrochim. Acta, 2012, 30, 53-65. doi : 10.4152/pea.201201053

8. M.A. Abu-Dalo, A.A. Othman and N.A.F. Al-Rawashdeh, Int. J. Electrochem. Sci., 2012, 7, 9303-9324. 
9. E.E. Oguzie, Y. Li and F.H. Wang, J. Colloid \& Interface Sci., 2007, 310, no. 1, 90-98. doi: $10.1016 /$ j.jicis.2007.01.038

10. P.C. Okafor, M.E. Ikpi, I.E. Uwah, E.E. Ebenso, U.J. Ekpea and S.A. Umoren, Corr. Sci., 2008, 50, no. 8, 2310-2317. doi: $\underline{10.1016 / j . c o r s c i .2008 .05 .009}$

11. M.S. Al-Otaibi, A.M. Al-Mayouf, M. Khan, A.A. Mousa, S.A. Al-Mazroae and H.Z. Alkhathlan, Corrosion inhibitory action of some plant extracts on the corrosion of mild steel in acidic media, Arabian J. Chem., 2014, 7, no. 3, 340-346. doi: 10.1016/j.arabjc.2012.01.015

12. I.B. Obot, N.O. Obi-Egbedi and S.A. Umoren, Antifungal drugs as corrosion inhibitors for aluminium in $0.1 \mathrm{M} \mathrm{HCl}$, Corros. Sci., 2009, 51, no. 8, 1868-1875. doi: 10.1016/j.corsci.2009.05.017

13. M. Mihit, S. El Issami, M. Bouklah, L. Bazzi, B. Hammouti, E. Ait Addi and R. Salghi, The inhibited effect of some tetrazolic compounds towards the corrosion of brass in nitric acid solution, Appl. Surf. Sci., 2006, 252, no. 6, 2389-2395. doi: 10.1016/j.apsusc.2005.04.009

14. S. El Issami, L. Bazzi, M. Mihit, B. Hammouti, S. Kertit, E. Ait Addi and R. Salghi, Triazolic compounds as corrosion inhibitors for copper in hydrochloric acid, Pigm. Resin Technol., 2007, 36, no. 3, 161-168. doi: 10.1108/03699420710749027

15. E.M. Sherif and Su-M. Park, Inhibition of copper corrosion in $3.0 \% \mathrm{NaCl}$ solution by Nphenyl-1,4-phenylenediamine, J. Electrochem. Soc., 2005, 152, no. 10, B428-B433. doi: $10.1149 / 1.2018254$

16. A. Yildirim and M. Cetin, Synthesis and evaluation of new long alkyl side chain acetamide, isoxazolidine and isoxazoline derivatives as corrosion inhibitors, Corros. Sci., 2008, 50, no. 1, 155-165. doi: 10.1016/j.corsci.2007.06.015

17. J.R.B. Thavamani, E. Rani and T. Jeyaraj, Inhibition of the corrosion of aluminium in alkaline medium by 1-(phenyl)-3-(2-hydroxy phenyl)-propenone in the presence of tetrabutylammonium bromide, Chem. Sin., 2012, 0, no. 6, 1358-1368.

18. A.A. Mahmmod, I.A. Kazarinov, A.A. Khadom and H.B. Mahood, Experimental and theoretical studies of mild steel corrosion inhibition in phosphoric acid using tetrazoles derivatives, J. Bio- and Tribo-Corrosion, 2018, 4, no. 4, 58. doi: 10.1007/s40735-018$\underline{0171-y}$

19. D.N. Komov, A.A. Mahmmod, A.A. Matikenova, L.A. Isaicheva, A.P. Kriven'ko and I.A. Kazarinov, Effect of tetrazolic corrosion inhibitors on the corrosion and electrochemical behavior of steel in phosphoric acidic solutions, Izvestiya Sarat. un-ta. Novaya seriya. Biologiya. Khimiya. Ekologiya, 2014, 14, no. 2, 32-38 (in Russian).

20. K.F. Khaled, Adsorption and inhibitive properties of a new synthesized guanidine derivative on corrosion of copper in $0.5 \mathrm{M} \mathrm{H}_{2} \mathrm{SO}_{4}$, Appl. Surf. Sci., 255, 1811-1818. doi: 10.1016/j.apsusc.2008.06.030

21. J. Cruz, R. Martnez, J. Genesca, E. Garcea-Ochoa, J. Electroanal. Chem., 2004, 566, 111. doi: $\underline{10.1016 / j . j e l e c h e m .2003 .11 .018}$ 
22. R. Solmaz, G. Kardaş, B. Yazici and M. Erbil, Colloids Surf. A, 2008, 312, no. 1, 7-17. doi: 10.1016/j.colsurfa.2007.06.035

23. M. Prajila, J. Sam, J. Bincy and J. Abraham, J. Mater. Environ. Sci., 2012, 3, no. 6, 1045-1064.

24. M. Larouj, M. Belayachi, H. Zarrok, A. Zarrouk, A. Guenbour, M. Ebn Touhami, A. Shaim, S. Boukhriss, H. Oudda and B. Hammouti, Pharma Chem., 2014, 6, no. 3, 373-384.

25. M. Larouj, H. Lgaz, H. Zarrok, H. Serrar, H. Zarrok, H. Bourazmi, A. Zarrouk, A. Elmidaoui, A. Guenbour, S. Boukhris and H. Oudda, J. Mater. Environ. Sci., 2015, 6, no. 11, 3251-3267.

26. Y. El Kacimi, M.A. Azaroual, R. Touir, M. Galai, K. Alaoui, M. Sfaira, M. Ebn Touhami and S. Kaya, Euro-Mediterr. J. Environ. Integr., 2017, 2, no. 1. doi: $\underline{10.1007 / \mathrm{s} 41207-016-0011-8}$

27. M. Larouj, M. Belkhaouda, H. Lgaz, R. Salghi, S. Jodeh, S. Samhan, H. Serrar, S. Boukhris, M. Zougagh and H. Oudda, Pharma Chem., 2016, 8, no. 2, 114-133.

28. A. Popova, M. Christov and A. Zwetanova, Effect of the molecular structure on the inhibitor properties of azoles on mild steel corrosion in $1 \mathrm{M}$ hydrochloric acid, Corros. Sci., 2007, 49, no. 5, 2131-2143. doi: 10.1016/j.corsci.2006.10.021

29. U.J. Naik, V.A. Panchal, A.S. Patel, N.K. Shah, J. Mater. Environ. Sci., 2012, 3, 935.

30. A. Mahmmod, M.H. Ismael, A.A. Fadhil and N.H. Kurshed, Int. J. Corros. Scale Inhib., 2019, 8, no. 2, 356-365. doi: 10.17675/2305-6894-2019-8-2-15

31. B.E. Brycki, I.H. Kowalczyk, A. Szulc, O. Kaczerewska and M. Pakiet, Organic corrosion inhibitors, Corrosion Inhibitors, Principles and Recent Applications, 2018. doi: $10.5772 /$ intechopen.72943

32. L.L. Shereir, Corrosion, Vol. 2, $2^{\text {nd }}$ Edition, Newnes-Butterworths, London, 1977.

33. Z.P. Demko and K.B. Sharpless, Preparation of 5-Substituted 1H-Tetrazoles from nitriles in water, J. Org. Chem., 2001, 66, no. 24, 7945-7950. doi: 10.1021/jo010635w 